\title{
Die Schweiz und die Revision der Pariser Verbandsübereinkunft
}

La Suisse et les enjeux des négociations internationales en vue de la révision de la convention de Paris

\section{Andràs November}

\section{OpenEdition}

\section{Journals}

Édition électronique

URL : http://journals.openedition.org/sjep/1003

DOI : 10.4000/sjep.1003

ISSN : 1663-9677

Éditeur

Institut de hautes études internationales et du développement

Édition imprimée

Date de publication : 1 janvier 1984

Pagination : 177-194

ISSN : 1660-5926

Référence électronique

Andràs November, «Die Schweiz und die Revision der Pariser Verbandsübereinkunft », Schweizerisches Jahrbuch für Entwicklungspolitik [En ligne], 4 | 1984, mis en ligne le 03 février 2013,

consulté le 08 septembre 2020. URL : http://journals.openedition.org/sjep/1003 ; DOI : https://doi.org/ 10.4000/sjep.1003

Ce document a été généré automatiquement le 8 septembre 2020

(c) The Graduate Institute 


\title{
Die Schweiz und die Revision der Pariser Verbandsübereinkunft
}

\author{
La Suisse et les enjeux des négociations internationales en vue de la révision de \\ la convention de Paris
}

Andràs November

\section{NOTE DE L'ÉDITEUR}

Zusammenfassung auf Deutsch. Volltext auf Französisch in Annuaire suisse de politique de développement: „La Suisse et les enjeux des négociations internationales en vue de la révision de la convention de Paris", http://aspd.revues.org/1168.

\section{RÉSUMÉS}

Die Revision des internationalen Patentrechts ist ein wichtiger Verhandlungspunkt in den NordSüd-Verhandlungen; Patente sind wichtige Bestandteile im Industrialisierungsprozess und beim Technologietransfer. Basis des Patentrechts ist ein gegenseitiger Vertrag zwischen dem Erfinder und der Gesellschaft: Einerseits eine Anerkennungsurkunde auf das geistige Eigentum einer Erfindung, andererseits die Möglichkeit des Gebrauchs der Erfindung zum gesellschaftlichen Nutzer. Das Patent schützt den Erfinder während einer bestimmten Zeit, jedoch höchtens während zwanzig Jahren vor Nachahmung. Das internationale Patentrecht wurde erstmals 1883 in der Pariser Verbandsübereinkunft geregelt und wurde seither sechsmal revidiert. Die letzte Revision fand 1967 in Stockholm statt. Heute haben 92 Staaten die Verbandsübereinkunft unterzeichnet. Die Schweiz gehört zu den Gründungsmitgliedern. Das Sekretariat befindet sich in 
Genf. Jährlich werden weltweit rund 100.000 Erfindungen gemacht. Die Schweiz gehört mit jährlich durchschnittlich 18.000 Patentgesuchen zu den wichtigen Industrieländern im Bereich der technologischen Innovation. Sie ist Verfechterin der geltenden strengen Regelung des internationalen Patentrechts. Für die Entwicklungsländer bedeutet die aktuelle Fassung ein Hindernis für die eigene Entwicklung. Nur $6 \%$ der heute gültigen Patente wurden in der Dritten Welt erteilt und rund $95 \%$ der von Ausländern gehaltenen Patente werden nicht in der lokalen Produktion verwertet, sondern werden als patentrechtlich geschützte Fertigprodukte importiert. Eine Studie der UNCTAD hat diese ungünstigen Auswirkungen der geltenden Patentregelung für die Entwicklungsländer nachgewiesen. Die Entwicklungsländer verlangen deshalb die Revision des Patentrechts, welches Bestandteil der Neuen Weltwirtschaftsordnung werden soll.

In den Revisionsverhandlungen wurden bis jetzt in den heftig diskutierten Punkten Erfinderzertifikat, exklusive Zwangslizenzen und Vorzugsbehandlung für die Entwicklungsländer keine Fortschritte erzielt. Das Erfinderzertifikat ist die in der Sowietunion und in einigen sozialistischen Entwicklungsländern gültige Regelung des Patents, sie soll diesem gleichgestellt werden. Die Forderung nach exklusiven Zwangslizenzen kommt von den Entwicklungsländern, welche eine gewisse Pflicht zur Ausübung der Patente verlangen. Die ebenfalls von den Entwicklungsländern beantragte bevorzugte Behandlung der Patentanträge aus der Dritten Welt wird von in Patentvergaben weniger dotierten Industrieländern wie Kanada und Australien abgelehnt.

Die Schweiz verteidigt das geltende internationale Patentrecht in seiner heute gültigen Fassung ; sie ist jedoch zu gewissen Konzessionen an die Entwicklungsländer bereit. Die Haltung des Vorort ist unnachgiebig, er möchte das Patentrecht ohne jegliche Konzessionen noch verstärken. 